\title{
AVALIAÇÃO DAS PERDAS DE ÁGUA NOS SISTEMAS DE ABASTECIMENTO NO BRASIL: EVOLUÇÃO, CONJUNTURA E PERSPECTIVAS
}

Otávio Henrique Campos Hamdan - camposhamdan@ yahoo.com.br

Universidade Federal de Minas Gerais

Raula Greice de Castro Resende - raulascastro@ hotmail.com

Universidade Federal de São João del-Rei

Ana Luisa Saraiva de Souza - analuisa_port@ hotmail.com

Universidade Federal de Viçosa 


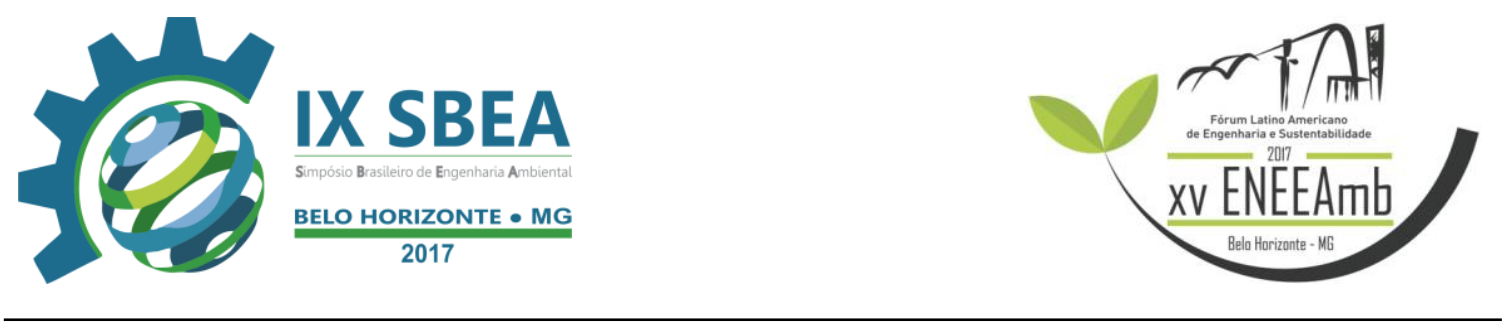

\section{RESUMO}

Um dos principais desafios na operação dos sistemas de abastecimento de água é o combate às perdas. Embora seja um problema amplamente conhecido, diversos sistemas apresentam elevados índices de perdas na distribuição. Diante desse cenário, o presente trabalho apresenta a evolução desse índice no Brasil, assim como a atual conjuntura e as perspectivas das perdas de água nos sistemas de abastecimento do país frente às metas estabelecidas no Plansab. Para tanto, o estudo foi dividido em três etapas metodológicas, sendo elas a (i) avaliação da série histórica do índice de perdas no Brasil, (ii) avaliação do atual índice de perdas no Brasil e (iii) comparação dos atuais índices de perdas com as metas do Plansab. Foram utilizadas informações sobre o índice de macromedição, micromedição e de perdas na distribuição disponibilizadas pelo Sistema de Informações sobre Saneamento (SNIS), em referência a 2966 municípios brasileiros. Por meio dessas informações verificou-se que diversos municípios apresentam fragilidade das informações relativas ao índice de perdas na distribuição, devido à estimativa dos volumes produzidos e consumidos. Além disso, percebeu-se que o índice de perdas sofreu variações ao longo dos anos, chegando ao índice de 36,7\% em 2015, um pouco acima da meta estabelecida pelo Plansab para 2018. Apesar disso, 440 municípios, dentre os amostrados, sequer alcançaram a meta estabelecida pelo Plansab para 2010, indicando a necessidade de investimentos continuados no setor para que os índices desejados sejam alcançados.

Palavras-chave: Sistema de abastecimento de água, Perdas, Plansab.

\section{INTRODUÇÃO/OBJETIVO}

As perdas de água ocorrem em todos os sistemas de abastecimento e pode ser considerado um dos maiores desafios na operação dos sistemas. Eles podem ocorrer desde a captação de água até os hidrômetros das economias (TRATA BRASIL, 2017).

De maneira geral, as perdas de água são resultado do volume perdido entre aquele produzido e o medido pelos hidrômetros. No entanto, as perdas não são apenas aquelas decorrentes de vazamentos em tubulações, denominadas perdas reais, elas também estão relacionadas aos erros de medição nos hidrômetros e até mesmo às ligações clandestinas, 


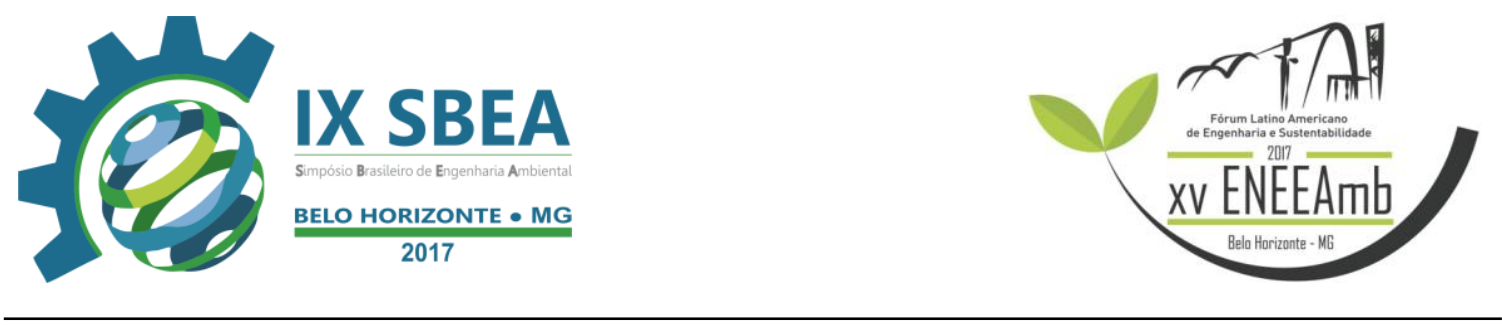

em que a água é consumida, mas não faturada. Essas perdas decorrentes de consumos não faturados são denominadas perdas aparentes (TARDELLI, 2016).

O combate às perdas de água mostra-se importante por diversos motivos, sejam eles ambientais ou financeiros. Dentre eles, sob a ótica dos ônus ao prestador, destacamse os prejuízos financeiros causados pelos altos índices de perdas, tendo em vista que a água perdida no sistema de distribuição recebe todo o tratamento para potabilizá-la e, ao fim, não é faturada. Além desse custo, ainda agregam-se aqueles necessários para bombeamento e manutenção. Adicionalmente, diante do cenário de escassez hídrica, os prejuízos ambientais de elevados índices de perdas de água mostram-se evidentes (ALEGRE et al., 2005).

De encontro às necessidades de prover sistemas de distribuição de água cada vez mais eficientes, o Plano Nacional de Saneamento Básico (Plansab) surge trazendo metas específicas para o índice de perdas na distribuição. Nesse sentido, ficam estabelecidos, por região do país, metas a serem alcançadas a curto, médio e longo prazo (MINISTÉRIO DAS CIDADES, 2013).

Nesse sentido, o presente trabalho objetiva, por meio das informações do Sistema Nacional de Informações sobre Saneamento (SNIS), avaliar a evolução e atual conjuntura do índice de perdas na distribuição no Brasil, assim como analisar as perspectivas desse índice frente às metas estabelecidas no Plansab.

\section{METODOLOGIA}

A fim de cumprir os objetivos do presente estudo, a metodologia subdivide-se em três etapas principais, sendo elas:

(i) Avaliação da série histórica do índice de perdas no Brasil;

(ii) Avaliação do atual índice de perdas no Brasil;

(iii) Comparação dos atuais índices de perdas com as metas do Plansab.

O estudo é uma análise exploratória das informações correlatas às perdas de água disponibilizadas pelo SNIS, principalmente no que se refere ao índice de perdas na distribuição, o qual é calculado pela razão entre o volume distribuído não consumido e o volume total distribuído, desconsiderando o volume importado. 


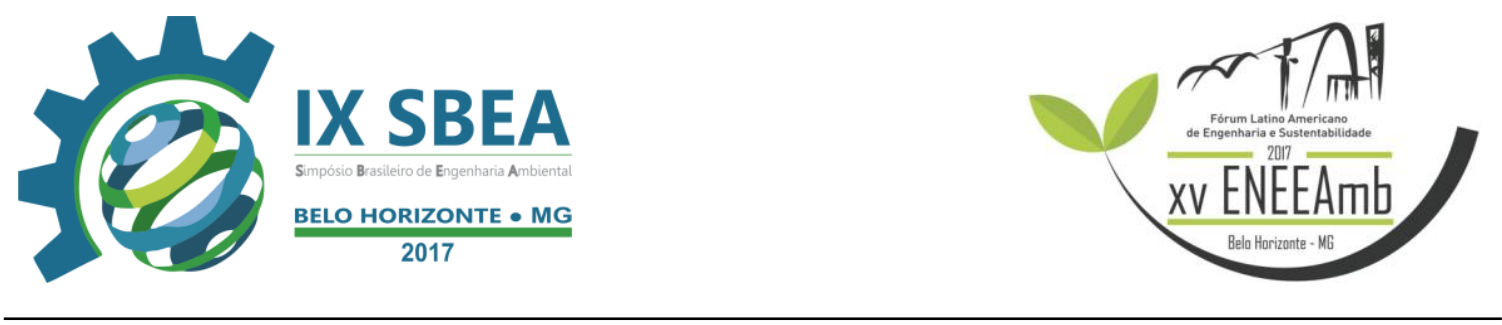

Como etapa prévia ao trabalho, realizou-se a seleção da amostra de municípios pautando-se em três critérios: anomalia das informações, índice de micromedição e índice de macromedição. Foram selecionados, portanto, os municípios que apresentaram índices de perdas na distribuição positivos e menores de 100\%, assim como aqueles com índices de micromedição e macromedição acima de 90\%. Desse modo, acredita-se que possíveis erros de interpretação serão mitigados, tendo em vista a eliminação de municípios com índice de perdas fora da faixa admissível e a diminuição dos volumes estimados por meio da limitação dos índices de macromedição e micromedição.

A primeira etapa permitiu a avaliação da evolução do índice de perdas no Brasil. O SNIS dispõe de informações relativas às perdas de água desde 1995, no entanto avaliouse a evolução desse índice no século XXI, ou seja, a partir do ano 2000. A avaliação consistiu na interpretação gráfica da evolução do índice de perdas e na análise de gráficos box-plot com o intuito de verificar o comportamento do índice ao longo dos anos.

A segunda etapa metodológica permitiu compor o panorama atual de perdas no país. Para tanto, avaliou-se as informações do índice de perdas na distribuição com os dados mais atualizados do SNIS, referentes ao ano de 2015. Nesse sentido, foram identificadas as regiões com melhores e piores índices.

Por fim, a terceira etapa consistiu na comparação entre os índices de perdas dos municípios amostrados e as metas para 2010 e 2018 dispostas no Plansab, para as diversas regiões do Brasil, permitindo a identificação dos locais em que as metas apresentadas pelo plano não foram cumpridas.

\section{RESULTADOS E DISCUSSÃO}

Dentre os 5570 municípios brasileiros, 5299 (95\%) apresentaram informações no SNIS do índice de perdas na distribuição entre 2000 e 2015. Dentre esses municípios, 2966 (53\%) foram selecionados para o presente estudo, considerando os critérios apresentados na metodologia. Vale destacar que apenas um município da região norte do país compôs a amostra, tendo em vista que os municípios dessa região apresentam demasiado déficit de informações relacionadas ao índice de perdas. De maneira geral, os municípios da região norte não apresentam a informação de índice de perdas na distribuição disponível ou apresentam essa informação com valor nulo. 


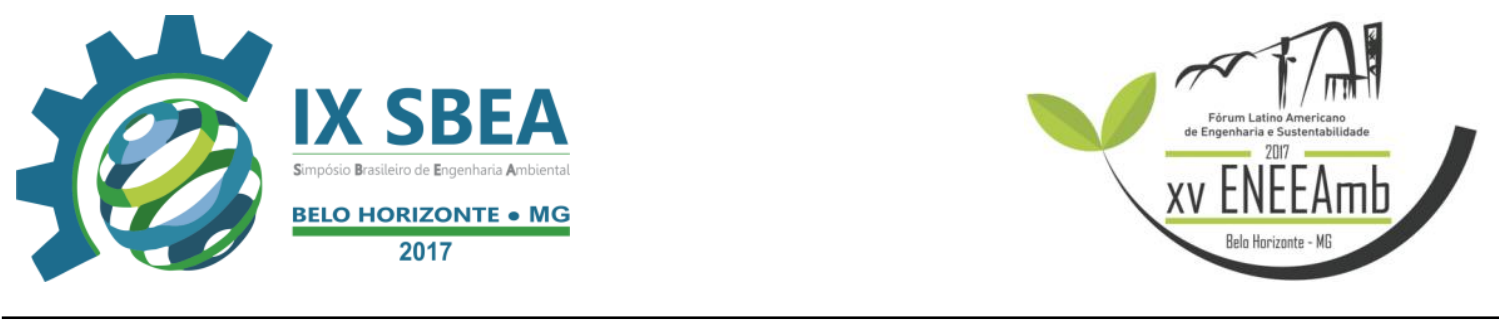

Conforme Figura 1 (a), desde 2000 o índice de perdas na distribuição sofreu variações ao longo dos anos, chegando a 40,9\% em 2001 e 35,9\% em 2010, o menor e maior índice dentre os anos avaliados, respectivamente. Em termos de perfil, conforme Figura 1 (b), é possível verificar que em 2001 houve uma maior variabilidade dos índices.
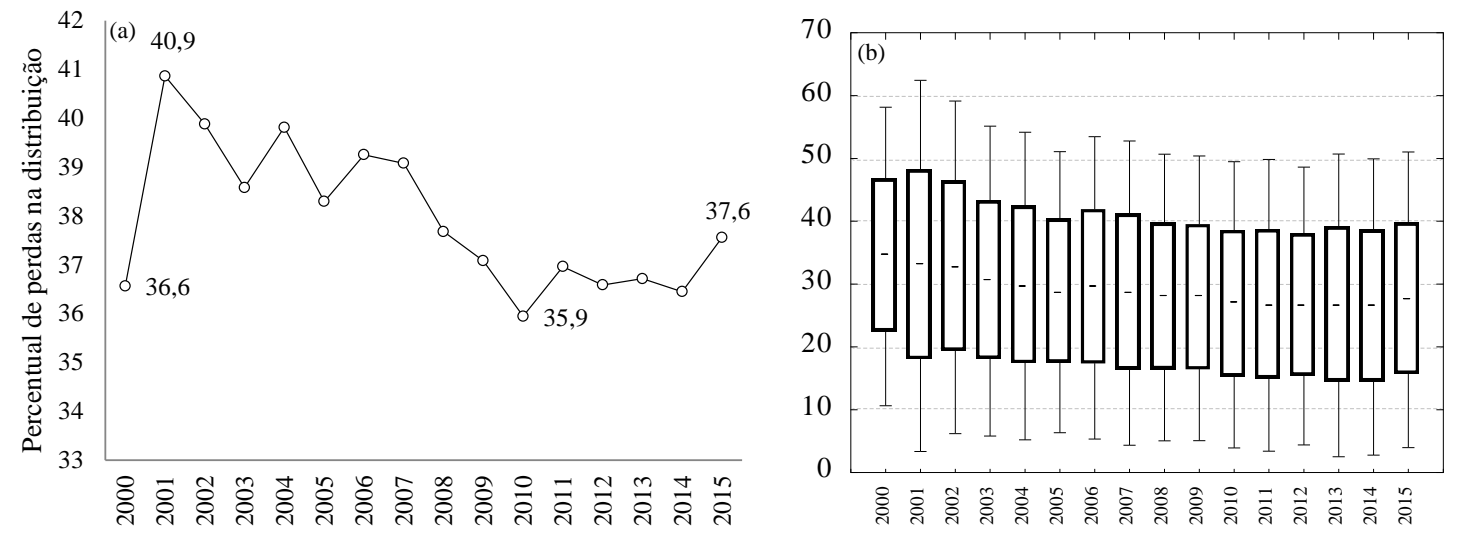

Figura 1 - (a) Evolução do índice de perdas na distribuição no Brasil e (b) boxplot do índice de perdas dos municípios amostrados.

Como pode ser observado, após o pico de 40,9\% de perdas em 2001, o índice passou por períodos de aumento e de diminuição. Observa-se que o período de 2007 a 2010 incorreu em um período de decréscimo continuado, seguido de um período de estabilização de 2011 a 2014. Pelo box-plot verifica-se que a partir de 2005 o perfil do índice é bem similar, em termos de variabilidade e média. Portanto, comparando os gráficos dispostos na Figura 1, pode-se inferir que a diminuição do índice de perdas no Brasil, como o observado entre 2006 e 2010, não foi acompanhada pela alteração do perfil geral dos índices nos municípios. Esse comportamento pode ser explicado pelo fato das melhorias em perdas ocorrerem em municípios pontuais, que proporcionaram diminuição do índice global em um determinado período, mas foram incapazes de alterar o perfil geral do índice.

O índice de perdas na distribuição é de 37,6\% nos municípios amostrados. Considerando, conforme Tardelli (2016), que aproximadamente dois terços das perdas são reais, ou seja, associadas à perda física de água, presume-se que no ano de 2015 foram perdidos 1,7 bilhões de metros de água, apenas nos municípios amostrados (53\% dos municípios brasileiros). Esse volume seria suficiente para preencher um sistema 


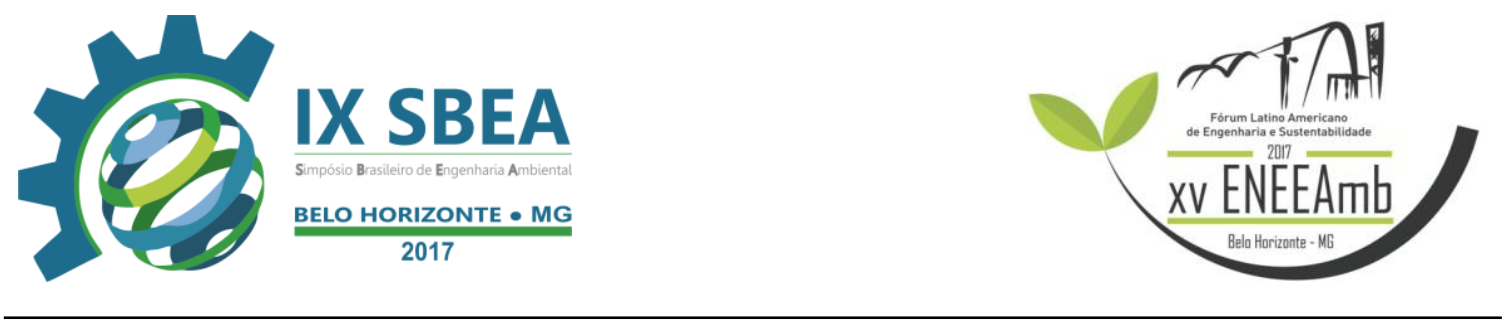

Cantareira e meio ou abastecer, diariamente, uma população equivalente à de Belo Horizonte $^{1}$. Além disso, segundo ABES (2013), estima-se que a redução em 10 pontos percentuais do atual índice de perdas levaria a um ganho potencial das prestadoras de serviços brasileiras de aproximadamente 21 bilhões de reais.

Dos dez municípios com maiores índices de perdas, dentre os amostrados, sete estão localizados na região nordeste, sendo três do estado do Rio Grande do Norte. Em contrapartida, dos dez municípios com menores índices, seis estão localizados na região sul, sendo quatro pertencentes ao estado do Rio Grande do Sul.

Segundo o Ministério das Cidades (2017) o índice de perdas no Brasil é de 36,7\%. Em termos gerais, o país está no caminho para cumprir a meta para 2018 (36\%) estabelecida no Plansab (MINISTÉRIO DAS CIDADES, 2013). Além da meta nacional, existem metas para cada região do país, conforme dispõe a Tabela 1.

Tabela 1 - Metas do Plansab por região, para 2010 e 2018.

\begin{tabular}{|c|c|c|}
\hline \multirow{2}{*}{ Região } & Percentual de perdas na distribuição (\%) \\
\cline { 2 - 3 } & 2010 & 2018 \\
\hline Centro-Oeste & 34 & 32 \\
\hline Norte & 51 & 45 \\
\hline Nordeste & 51 & 44 \\
\hline Sudeste & 34 & 33 \\
\hline Sul & 35 & 33 \\
\hline
\end{tabular}

Diversos municípios estão distantes da meta de 2018 e outros ainda não cumpriram ao menos a meta determinada para o início da década. Dentre os municípios amostrados com informações no SNIS para o ano de 2015 (2346), 554 ainda não cumpriram a meta de 2018 e 440 se quer cumpriram a meta estabelecida para 2010, como pode ser observado na Figura 2.

${ }^{1}$ Considerando um consumo diário per capita de 175 litros. 

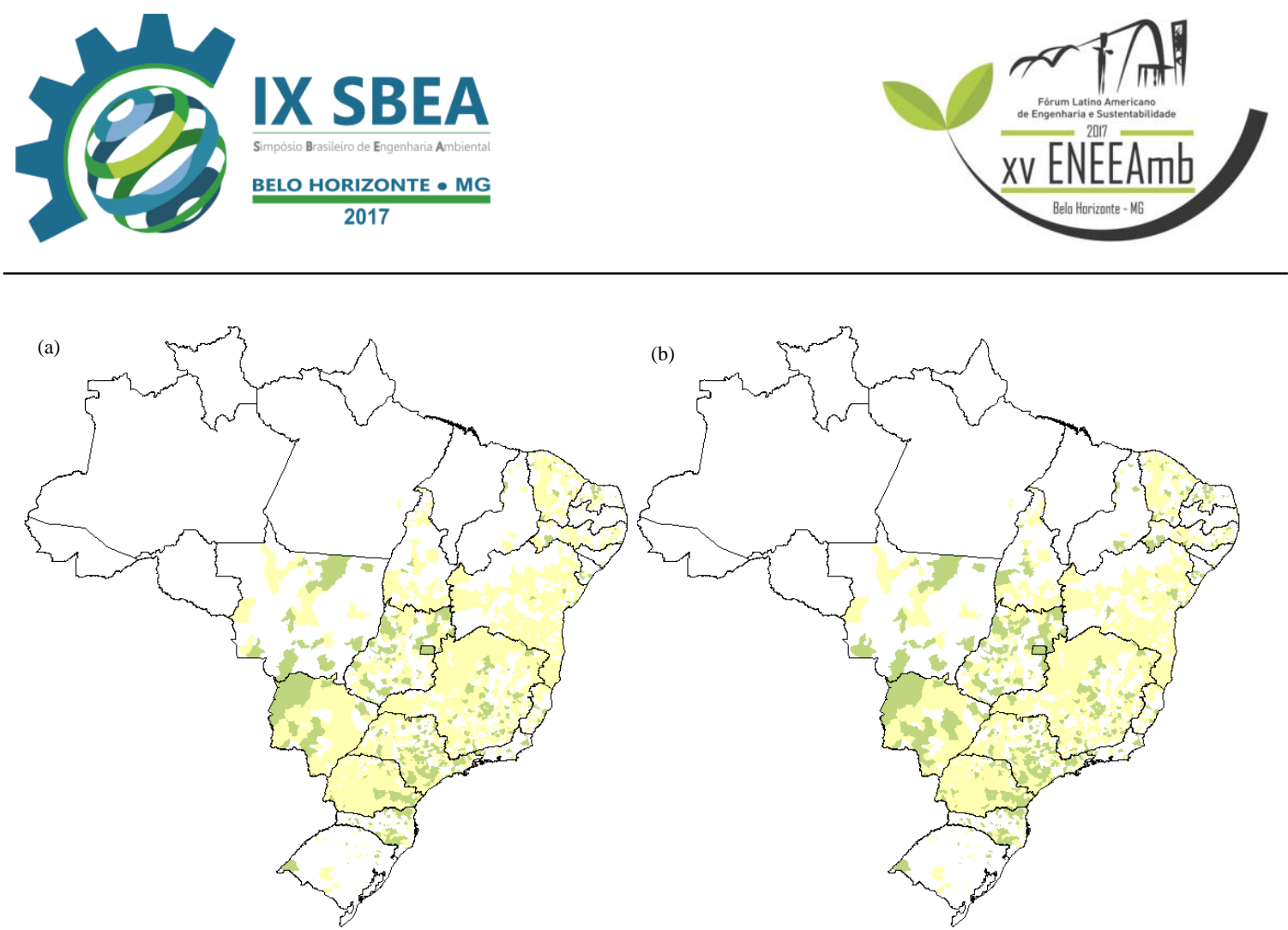

Figura 2 - Em amarelo os municípios que cumpriram e em verde os que não cumpriram a meta do Plansab para (a) 2010 e (b) 2018.

Como pode ser observado na Figura 2, diversos municípios (em branco) não compuseram a amostra utilizada nesse estudo. A ausência desses municípios na amostra se deve ao fato desses apresentarem certa fragilidade nas informações disponibilizadas ao SNIS, seja pela ausência de informações ou pelo preenchimento inadequado. Além disso, diversos municípios foram excluídos da amostra por apresentarem índice de macromedição e/ou micromedição abaixo de $90 \%$, considerando que quanto menores são esses índices maiores as fragilidades da informação, tendo em vista que parte do volume é estimado e não medido de fato.

\section{CONCLUSÕES/RECOMENDAÇÕES}

Com base na amostra de municípios analisada no presente estudo é possível traçar um panorama da evolução, conjuntura e perspectivas no que se refere ao índice de perdas no Brasil. Para tanto utilizou-se dados do SNIS, tanto da série histórica disponível como para o último ano de informações.

Mediante uma análise preliminar, verificou-se que diversos municípios não fornecem informações suficientes para composição do índice de perdas na distribuição ou, por ora, apresentam esse índice nulo. Além disso, foi possível observar por meio dos índices de macromedição e micromedição que grande parte dos volumes produzido e 


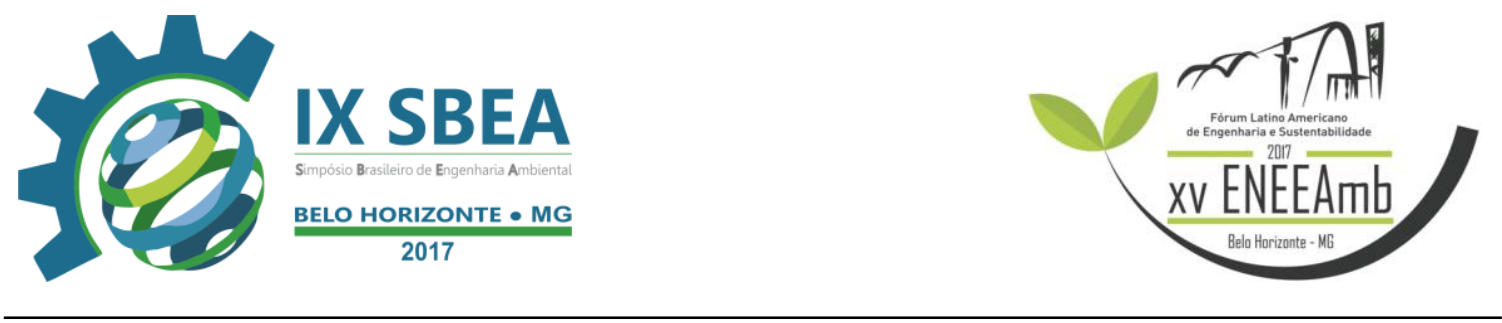

consumido são estimados, culminando em índices frágeis e pouco confiáveis. Para minimizar os erros da análise desse estudo, esses municípios foram removidos da amostra.

Percebe-se que o índice de perdas sofreu variação ao longo dos anos, incorrendo em períodos de queda, mas também em acréscimos acentuados. Com isso, segundo informações do SNIS, atualmente o índice de perdas no Brasil é de aproximadamente 36,7\%, um pouco acima da meta estabelecido pelo Plansab para 2018.

No entanto, embora o cenário aponte para o cumprimento da meta, observa-se que diversos municípios não cumpriram a meta estabelecida pelo Plansab para 2010. Dentre os 2346 municípios avaliados, 440 apresentavam índice de perdas em 2015 acima daqueles previamente estabelecidos.

Esse cenário aponta para a necessidade de investimentos continuados no setor com vistas aos ganhos associados à mitigação das perdas, seja pela otimização dos custos operacionais dos sistemas de abastecimento de água ou pela diminuição do estresse hídrico nos mananciais em que a água é captada para abastecimento público.

\section{REFERÊNCIAS BIBLIOGRÁFICAS}

ABES. Disponível em: http://www.abes-sp.org.br/arquivos/perdas.pdf. Acesso em: 18 abr. 2017.

ALEGRE, H., COELHO, S. T., ALMEIDA, M. C., VIEIRA, P. Controle de perdas de água em sistemas públicos de adução e distribuição. Portugal: LNEC, 2005. 306 p.

MINISTÉRIO DAS CIDADES. Plano Nacional de Saneamento Básico. Brasília: Ministério das Cidades, 2013.

\section{Sistema Nacional de Informações sobre Saneamento: Diagnóstico dos} Serviços de Água e Esgotos - 2015. Brasília: Ministério das Cidades, 2017. 80 p.

TARDELLI, J. Aspectos relevantes do controle de perdas em sistemas públicos de abastecimento de água. Revista DAE, São Paulo, n. 201, p. 6-20, 2016. 173 p.

TRATA BRASIL. Disponível em: http://www.tratabrasil.org.br/perdas-de-aguadesafios-ao-avanco-do-saneamento-basico-e-a-escassez-hidrica-2. Acesso em: 09 mai. 2017. 